Article

\title{
Security Net and Ambassadors for Social Inclusion? The Role of Intermediaries in Host-Refugee Relationships in Homestay Programs
}

\author{
Lara-Désirée Brinker \\ Department of Social and Cultural Anthropology, Autonomous University of Barcelona, Spain; \\ E-Mail: laradesiree.brinker@e-campus.uab.cat
}

Submitted: 14 May 2021 | Accepted: 9 September 2021 | Published: 15 December 2021

\begin{abstract}
In response to refugees' social marginalisation and lack of appropriate housing, homestay programs have emerged as a new approach to refugee accommodation. However, caring relationships between asylum-seekers and refugees and locals are prone to reproduce power imbalances. As a countermeasure, flatshares initiated by the organisation Refugees Welcome are created within a three-fold network of hosts, social workers, and volunteers. The volunteers serve as intermediaries and provide refugees with personalised support to become more rooted in society. Drawing on ethnographic fieldwork and thirty in-depth interviews with hosts, refugees, intermediaries, and social workers in Catalonia (Spain), this article explores the responsibilities and struggles of intermediaries in the hosting networks. Results show that intermediaries give refugees and hosts a sense of security during the flatshare and keep social workers informed, yet their role varies considerably.
\end{abstract}

\section{Keywords}

family hosting; housing; migration; refugees; volunteering

\section{Issue}

This article is part of the issue "In Good Company? Personal Relationships, Network Embeddedness, and Social Inclusion" edited by Miranda J. Lubbers (Autonomous University of Barcelona, Spain).

(C) 2021 by the author; licensee Cogitatio (Lisbon, Portugal). This article is licensed under a Creative Commons Attribution 4.0 International License (CC BY).

\section{Introduction}

Secure and safe housing is considered a fundamental human need and a crucial prerequisite for refugees' social integration (Ager \& Strang, 2008). As Phillimore and Goodson (2008, pp. 315-316) indicate, "finding a home is particularly symbolic as it marks the end of a journey and the point at which refugees can start to consider their wider need." A lack of stable and sanitary housing has been found to jeopardise refugees' wellbeing and physical health (Phillips, 2006).

Yet, refugees face difficulties transitioning from reception centres or specialised housing into the private local housing market due to insufficient knowledge of local procedures and discrimination (Adam et al., 2019). Support through local networks, and people who know the asylum application and transition process are crucial as refugees are particularly vulnerable and prone to exploitation during this transition phase (Provivienda,
2019). Often, refugees tend to settle with co-ethnics in disadvantaged areas (Colic-Peisker \& Tilbury, 2008).

As a response, hosting programs have emerged, which provide an alternative form of refugee accommodation (Ran \& Join-Lambert, 2019). In such programs, resident families or individuals offer a spare room to refugees for a limited time. They are expected to facilitate refugees' social integration by providing a safe and stable living environment and introducing refugees to local culture and customs by sharing daily life. However, such arrangements can be prone to reproduce power imbalances. Therefore, the international organisation Refugees Welcome additionally assigns an intermediary to the family-refugee arrangement, i.e., volunteers who facilitate the first meeting between the two parties and accompany them during the arrangement.

While relationships between residents and refugees in family hosting programs (Brinker, 2020; Ran \& Join-Lambert, 2019) and befriending programs (Behnia, 
2007; Charbonneau \& Laaroussi, 2003; Stock, 2019) have been studied by various researchers, the impact of local intermediaries in family hosting programs has not been investigated before. The present study occupies this niche in the literature by exploring the role of intermediaries in host-refugee dyads, examining whether they can contribute to the formation of local social capital and compensate for potential power differentials in refugee-host relationships observed elsewhere. Thus, the research question guiding this article is: What do intermediaries contribute to host-refugee relationships in family hosting programs? More specifically, do they provide social support to the refugees, and do they compensate for potential power differentials in these relationships? To answer these questions, I draw on qualitative research conducted in the organisation Refugees Welcome in Catalonia (Spain).

The structure of this article is as follows. The next section presents the theoretical framework, which discusses concepts of power imbalance and social connectedness. Subsequently, I present asylum seeking in the Spanish context and the Refugees Welcome's activity in Catalonia. In Section 4, I describe the methodology adopted to conduct the research. Then, I present the findings, following the themes that emerged from the interviews, and finally, I draw my conclusions regarding the research questions and discuss their implications.

\section{Theoretical Framework}

The insufficiency of government-led housing for asylum seekers and refugees in many European societies has led to the emergence of family hosting programs in Europe (Ran \& Join-Lambert, 2019). Such programs tend to have a double objective: first, to provide safe and secure housing, and second, to aid local integration. Indeed, social integration goes far beyond offering permanent accommodation to refugees (Kourachanis, 2019). Establishing social connectedness with local communities and social cohesion, these local contacts are crucial to refugees' sense of belonging and integration (Ager \& Strang, 2008). As refugees forcibly left their social and cultural surroundings and lost their support networks, they must build new local social capital from scratch (Hebbani et al., 2018). Such relationships can have varying tie strength, defined by Granovetter (1973) as a combination of the duration of a relationship, emotional intensity, mutual confiding, and the exchange of reciprocal services. "Strong ties"-enduring, intimate, and supportive relationships - provide access to social resources and a sense of belonging. Yet, Granovetter argued that the more numerous, heterogeneous, and less densely connected "weak ties" are also essential for diffusing information, enabling access to housing or employment. A wide array of "weak" or "peripheral ties," particularly with locals, benefits social integration as weak ties may "enhance intimate ties" and take the function of strong ties when individuals lack such ties (Fingerman, 2009, p. 74). For asylum seekers and refugees, they also promote upward mobility (Wells, 2011) and a sense of security and belonging through regular contact with locals (Verdasco, 2019).

Recent studies on the impact of family-hosting in refugee integration in France and Spain (Brinker, 2020; Ran \& Join-Lambert, 2019), communal living between refugees and residents in Belgium (Mahieu \& Van Caudenberg, 2020), and foster care of unaccompanied young refugees in local families in England (Sirriyeh, 2013) show that flatshares between refugees and locals are largely beneficial in this respect. Not only do they provide housing, but host families also facilitated refugees' access to local social capital and positively impacted refugees' well-being (Ran \& Join-Lambert, 2019). Brinker (2020) and Sirriyeh (2013) further highlight the close emotional bonds developed between flatmates and the extended family members of residents, fostering a sense of belonging. Mahieu and Van Caudenberg (2020) emphasise the benefits of mutual learning in intercultural flatshares and highlight the importance of flatmates as easily accessible providers of informal social support.

However, research on host-refugee relationships also exposed that such flatshares might reproduce power imbalances (Brinker, 2020; Ran \& Join-Lambert, 2019). As Del Real (2019) explained for the US, the difference in legal status, rights, and social protection between documented and undocumented citizens is reproduced informally in mixed-status social relationships among friends, relatives, and acquaintances. Particularly when undocumented citizens relied partly on the resources to which documented citizens had access, documented citizens had the upper hand in these relationships, which could make these ties "toxic." Research on host-refugee relationships in family hosting programs shows that power imbalances manifested in different ways. First, although usually based on a formal contract, refugees and hosts often had a different say in rule-making, also due to the different status of rights regarding the property, and cultural differences often prevailed (Brinker, 2020; Ran \& Join-Lambert, 2019). Second, hosts' and refugees' expectations towards the flatshare often deviated as hosts wished for more family-like interactions (Brinker, 2020). Third, hosts were prone to interfering with refugees' private space and, knowing or unknowingly, sabotaged refugees' path to independence through overprotection (Ran \& Join-Lambert, 2019).

One way to manage this imbalance is intermediation. The NGO Refugees Welcome (see below) offers a family hosting program and pairs families and refugees with a local volunteer. This intermediary has various objectives: to extend the social support network of the refugee or asylum-seeker and, once the organisation has identified a suitable pairing, to verify housing conditions, facilitate the first meeting, and accompany the process throughout the period of co-living (Refugees Welcome, 2021d), giving both parties a sense of security. Furthermore, by taking up the role of intermediary, the volunteer also 
promotes the "welcoming culture" that aims to welcome refugees into society instead of excluding them, "a call for accepting those in need and encouraging support of the civil society in the integration of refugees" (Liebe et al., 2018, p. 2). Traditional befriending programs established for locals and refugees assume that "due to their formal citizenship, resident volunteers have privileged access to the relevant cultural, economic, or social capital needed to facilitate migrants' integration into society" (Stock, 2019, pp. 128-129). Befriending programs are a valuable resource for refugee integration (Behnia, 2007). Volunteers provide "emotional, informational and instrumental support," ranging from assistance in administrative tasks such as searching for a job or place to live to cultural orientation in the new society (Behnia, 2007, p. 3).

Nonetheless, the concept of an intermediary in a refugee-host dyad differs from traditional befriending programs, where befrienders do not usually serve as direct mediators. While befriending programs for residents and refugees have been studied by various researchers (Behnia, 2007; Charbonneau \& Laaroussi, 2003; Stock, 2019), the impact of local intermediaries in family hosting programs has not been investigated before. The present study, therefore, contributes to the literature by exploring the role of intermediaries in hostrefugee dyads, examining whether they can compensate for potential power differentials observed elsewhere.

\section{Refugees Welcome in Spain}

The number of asylum-seekers has increased significantly in Spain between $2014(5,952)$ and $2019(118,446)$. The majority comes from Latin-American countries such as Venezuela, Colombia, and Honduras. However, others come from the neighbouring country Morocco, various West African countries such as Mali, and large conflict zones in other continents such as Syria (Oficina de Asilo y Refugio, 2020). Spain follows a three-phased reception and integration system, allowing asylum seekers to stay between six to nine months at reception centres after a one-month admission process. Subsequently, during the six-month phase two, refugees can receive further economic aid and social services. When entering phase two, refugees are expected to leave government facilities and find a private place to stay. The process may be completed with a third phase, in which the beneficiary receives additional assistance or sporadic support in certain areas (Comisión Española de Ayuda al Refugiado, 2021). However, due to increasing rental prices (particularly in Madrid and Barcelona), xenophobia, gentrification, and landlords' discrimination, refugees are at risk of poverty and homelessness in Spain (Provivienda, 2019).

Founded in Germany in 2014, the international NGO Refugees Welcome serves as a broker by connecting local hosts with a spare room with refugees in search of housing. Refugees Welcome is active in Spain in six locations: Barcelona, Madrid, Valencia, the Balearic Islands, Galicia, and Murcia. As of March 2021, it has created 100 cohabitations in Spain and 1,869 globally (Refugees Welcome, 2021a; Refugees Welcome International, 2021). The NGO's concept is based on (a) matching hosts with refugees for a minimum of six months, considering each party's specific needs and (b) supporting the flatshare with the help of social workers and volunteers, called vínculos locales ("local links"). Volunteers are supposed to act as intermediaries to guide flatmates through the process and serve as independent persons of trust (Refugees Welcome, 2021b). Refugees Welcome promotes a culture of horizontality among all parties. Flatshares are agreed on by contract, and refugees are requested to contribute a minimum rental fee (Refugees Welcome, 2021c). The fee is intended to ensure that the different parties contribute within their own ability, providing ground for a sense of horizontality and equality. Publicly, the organisation portrays co-living as an enriching experience for all parties, underlined by pictures and videos from previous flatshares. Intermediaries are commonly presented as activists for the welcoming culture (Refugees Welcome, 2021c).

\section{Methodology}

Data stem from my doctoral research project on flatshares between refugees and locals in Spain. The methodology encompasses participant observation at the NGO Refugees Welcome, data analysis of all flatshares organised in Catalonia, and thirty qualitative interviews with refugees, hosts, intermediaries, and social workers from Refugees Welcome.

For participant observation, I conducted my fieldwork as a "volunteer ethnographer" (a term proposed by Garthwaite, 2016, p. 61, to describe the dual role of volunteer and ethnographer; cf. Hill O'Connor \& Baker, 2017), at the organisation's office from November 2019 to September 2020, revising the projects in Catalonia and participating in formal training and meetings for volunteers. Later, I also started volunteering as an intermediary for a new flatshare, which I continue to do until today.

With a social worker, I analysed the anonymised data that Refugees Welcome in Catalonia had collected of the thirty-nine flatshares they had organised between January 2017 and February 2020, involving thirty-nine refugees, thirty-three hosts, and twenty-nine intermediaries. The data concern participants' profiles, motivation, flatshare duration, conflicts, extensions, reasons to terminate, and the longevity of contact after flatshares ended. All individuals from whom data were collected accepted the terms and conditions stipulated by Refugees Welcome, including the use of the anonymised data by collaborators.

Last, I conducted thirty semi-structured qualitative interviews with eight refugees, eleven hosts, six intermediaries, and six social workers from Refugees Welcome. A social worker initiated the first contact. Later, I used snowball sampling to invite participants. Besides 
collecting demographic and socio-economic information, the interviews focused on the different responsibilities within the flatshare network, patterns of contact during and after the flatshare ended, and the expectations of the hosts, refugees, and social workers. The interviews took ninety minutes on average and were mainly carried out via Zoom between March and September 2020 due to the first wave of COVID-19 in Spain. The interviews with each party were held separately and confidentially in English or Spanish, languages with which all participants were conversant. The interviews were recorded with consent and later transcribed verbatim and coded and analysed using NVivo 1.0 (QSR International), following a combination of a priori and emergent codes.

\subsection{Sample}

The interview sample of refugees consisted of seven male and one female participant. The participants were between 23 and 40 years old. Only one was in his late fifties. This distribution mirrors the high proportion of young, single, male West Africans and Latin Americans applying for asylum in Spain. Four of the flatshares were still active when the interviews took place.

The hosts were eleven white, middle-class Spanish nationals (six male, five female). Eight were in their midfifties to mid-sixties, one between forty and fifty and two in their mid-thirties. Two of their flatshares were still active when the interviews took place.

Interviewed intermediaries were six middle-class females from Spain, Italy, and the US. Five were in their mid-twenties to mid-thirties, with one above forty years old. Two of their flatshares were still active at the time of the interview, and five claimed to still be in contact with at least the refugee. Among volunteers and hosts, only one volunteer had a professional affiliation with the field of refugee aid.

The social workers I interviewed were five female, middle-class Spanish nationals in their mid-twenties to mid-thirties. One was a paid part-time employee at Refugees Welcome; the others were volunteers themselves, with previous volunteering experience at migration-related social organisations or migrationrelated studies. Notably, all social workers had previously served as intermediaries. One was one of the NGO's founders.

\subsection{Ethics}

From the first moment I contacted the organisation, I have disclosed my nature as a PhD student focusing on cross-cultural flatshares and provided detailed information about my research and methodology. The organisation's leadership accepted me, and in mutual agreement I also accepted the role as a volunteer at Refugees Welcome ES. At every first interaction (such as in events) with members, volunteers, or refugees, I disclosed that I was a PhD student at the Autonomous University of
Barcelona, explained my research, and asked for consent to use observations confidentially in my research. For the interviews, I also explained the voluntary nature of participation and asked for consent. As it is a common policy at Refugees Welcome not to ask refugees or asylum seekers any triggering questions regarding their past, I did not ask such questions during the qualitative interviews. In this article, the data was anonymised, and names were replaced by pseudonyms. Although my participant observation as an intermediary in one familyhosting arrangement has informed my work, I have not described it explicitly in this article, as the other members of the arrangement would be able to recognise themselves and one another in such a description. Ethics approval for data collection was gained from the university's Institutional Review Board, the Ethics Committee on Animal and Human Experimentation (ID 5189).

\section{Results}

To unfold the perceived role of local buddies, I will first sketch the role of each network member and their expectations about the role of the intermediary. I will then discuss the different responsibilities intermediaries have within the family hosting network, ranging from facilitating the first contact between hosts and refugees and providing help to the refugee to different levels of interventions during the flatshare. Discussing these issues from the different points of view of hosts, refugees, intermediaries, and social workers allowed me to detect (dis)agreement in perceptions regarding social connectedness and power imbalances.

\subsection{The Hosting Network}

The concept of Refugees Welcome's family hosting network is based on a three-fold structure of support, comprising hosts, social workers, and intermediaries. To set the role of intermediaries into context within the family hosting network, I will briefly outline the roles and responsibilities of hosts and social workers based on my qualitative interviews.

In theory, hosts provide the core element in the hosting network: a safe and stable living environment for a fixed period. Refugees reported that hosts provided essential emotional and administrative support, often acted as advisers on cultural and everyday issues, and introduced refugees to their friends, families, or others. Six out of eight refugees named the host as someone they would consult if they needed help. The others mentioned other migrant friends and social workers of Refugees Welcome. When asked with whom they felt most safe in Spain, seven refugees named the same individuals, while one did not feel safe with anyone.

In contrast to hosts' emotional support, social workers represented stability and guidance supporting participants from the beginning of the process until, at least, the termination of the flatshare. Social workers 
mentioned that the management of hosts and intermediaries' expectations was a focal responsibility. Properly introducing the hosts and intermediaries to refugee aid through training sessions is seen as key. Refugees valued the fact that social workers provided them with tools to integrate in Spain, such as access to language classes, cultural activities, information on job vacancies, and training programs provided by the local government or other social organisations. Furthermore, social workers reached out to humanitarian organisations and local refugee reception centres to get the project known. As Refugees Welcome does not provide legal assistance for refugees, social workers from respective reception centres continued to provide guidance and legal assistance throughout phase two of the asylum application process.

Responsibilities of hosts and social workers thus followed a specific structure with clearly defined responsibilities. In contrast, the role of intermediaries appeared to be more flexible, adjusting to the needs of hosts and refugees.

\subsection{The Ideal Intermediary}

Intermediaries were seen as crucial by social workers for their personalised support:

When the flatshare starts, we [social workers] usually take a step back....If the intermediary and the flatshare get along well, it's the intermediary who supports them.... The intermediary serves as a reference when problems occur and, if everything goes well, is doing the follow-ups. (Anita, social worker)

If there is any query or anything they [intermediaries] don't know, we from the organisation are there to help. Still, we try to make the intermediaries the ones who are present [after the first encounter with the host]. (Laura, social worker)

As Refugees Welcome is an NGO, most social workers are volunteers. When the interviews took place, Refugees Welcome in Barcelona employed one social worker and two part-time marketing and project management professionals. Thus, from the organisation's perspective, intermediaries occupied an essential role in administrative support and accompanying migrants on their paths to autonomy. Furthermore, as intermediaries only attend one flatshare, they are closer to flatmates and better equipped to monitor and intervene.

Social workers emphasised respect for the refugees' privacy and the ability to handle racism and prejudice as essential skills of intermediaries:

They must be very respectful, and they cannot ask the refugees anything about their story and why they are here. Above all, they need to have a constructive approach. By this, I mean, if a host says something racist, they shouldn't get angry and say, "You are racist!" Instead, they should explain why we, as Refugees Welcome, don't identify with that phrase.... They have to be constructive because some people will say something without a bad intention....Some people need a bit of guidance and someone who explains a situation from a different perspective. If you can open this channel of trust, people often step forward and ask you more questions. (Éster, social worker)

Hosts agreed upon the crucial role of intermediaries, although they emphasised other skills:

It is good to feel accompanied by a third person. Someone who is there if you might need them. Someone who does a follow-up and checks on you independently or when all three of you are together. He [the intermediary] feels fundamental to me because when you have a doubt, someone is there. (Enric, host)

The intermediary is very important....First, you might think you don't need an intermediary. But after some time, problems and differences will appear, and you need one.... It is essential that an intermediary can listen, is peaceful, and knows how to reflect with calmness. (Maria, host)

I think it is essential to have a third person from outside the house. (Hugo, host)

From the interviews with hosts, it was found that mentoring and communication skills, empathy, patience, and pro-activity were traits of the ideal intermediary:

[Intermediaries] should know how to listen and how to empathise with both sides. Every relationship is different, and so are the needs. Sometimes refugees and hosts might need more practical help, like finding a job. Some might have the typical problems of living together, like cleaning, and in some cases, there might be more emotional issues... like things you don't like about the other person. So they have to be open-minded about this. (Enric, host)

A good match between volunteers, refugees, and hosts was also valued. Maria, a Spanish woman in her sixties, hosted Alaya, a young South-Asian woman. Maria believed that depending on the refugees' culture, refugees and hosts should have the same gender to avoid discomfort on both sides and that a good demographic match was equally important for volunteers and refugees:

The intermediary is essential....In the beginning, the young man we had didn't feel comfortable. I believe it was more a thing about him being a man and her a woman. He was young, married, and had a small 
child....If Alaya was a young woman from Venezuela or at least spoke some Spanish, things could have gone differently. (Maria, host)

Although the organisation emphasises matching volunteers and refugees according to demographic, cultural, and interest-related similarities, same-gender pairings remain challenging, as $72 \%$ of refugees accommodated in flatshares in Catalonia were male adults, while $90 \%$ of intermediaries were female.

Like hosts, refugees also highlighted the importance of a third party in the relationship. However, when asked about the ideal intermediary, they would not ascribe them specific characteristics or mention gender issues. The mere fact of having another party to turn to seemed most critical:

It is not only the apartment, but they also follow the flatshare and give you someone like a mentor to see how the flatshare is going. If everything is all right and if you feel comfortable. I think for us migrants, it is vital. To have someone who is looking after you to see if you are doing well. I think the person [refugee] feels more comfortable and confident. (John, refugee)

I was relieved....When the social worker told me I would stay in this apartment, but there would be someone [intermediary] for me... she didn't say there would be someone to monitor or control me.....If I had any conflict or problem, this person would be there for me if anything is not ok. It was like a backup relief for me. It doesn't stress me. Ana [intermediary] is like a house guardian for me. It was more than a relief. It was like, thank God; I have somebody to talk to. (Samuel, refugee)

To conclude, all interviewees valued the role of intermediaries to complement host-refugee dyads flexibly.

\subsection{Breaking the Ice}

Social workers reported that doubts and lingering fears often characterise the weeks before the flatshare. After a wave of joyful anticipation, hosts often struggle with their expectations and uncertainties about the process. Typical concerns of hosts include managing misunderstandings, getting along well, and proceeding if one party does not feel comfortable cohabiting. In contrast, refugees were most anxious about the conditions of the spare room.

One of the intermediaries' responsibilities is getting to know hosts and migrants separately and accompanying their first encounter before both parties sign the rental contract. Both hosts and refugees described intermediaries as crucial to breaking the ice at the first encounter and helping the parties connect:

To me, the intermediary is one of the capital figures of the organisation. It is like at the beginning of a new friendship. You get along well or not. In some cases, this might not work out, but the intermediary is someone who makes [the first encounter] easier for hosts and refugees. (Ignacio, host)

Carmen, a Spanish lady in her fifties, and her family hosted Eduardo from Central America. She was slightly nervous about her new flatmate. Still, when the social worker and later the intermediary told her about Eduardo and introduced him, the day he moved in, he was no stranger anymore:

Our intermediary was the first to tell us about the person who was coming. We didn't know anything, but by how she explained him to us, we already had an idea of him in our mind....She [intermediary] was such a nice girl, very natural....She had a good relationship with Eduardo, and she transferred this bond to us. And we continued with the affection she had for him. (Carmen, host)

\section{Eduardo perceived this in the same way:}

My intermediary went with me to Carmen and Roger's house. It was very nice because she wanted to help me and when we went to see the family for the first time, I could feel they wanted to help me as much as she did. (Eduardo, refugee)

Intermediaries usually accompanied refugees on their first day of the flatshare, assisted with carrying boxes, and stayed with the new flatmates until they felt comfortable and settled. They also sometimes acted as translators or interconnectors. When Faizal from Morocco moved in with Hugo, Faizal was not conversant in Spanish and had difficulties understanding Hugo. To their benefit, their intermediary was from Morocco and translated between the two:

Our intermediary was here on the first day. He was able to translate everything I said to Faizal. It was helpful. (Hugo, host)

Similarly, Enric reflected on how intermediary Paula helped to connect him with his flatmate Musa:

Paula helps me a lot to understand Musa. When Paula comes to our house, Musa is always very open. I think she is doing an excellent job. Paula helps us because she knows how to approach him. She is also very patient and, I don't know, doesn't expect anything from the moments with him. She is just there for him. (Enric, host)

Intermediaries thus serve as essential bridges, carefully preparing hosts and migrants for living together and connecting them. 


\subsection{A Helping Hand}

Once the flatshares had been active for some weeks, relationships between hosts and refugees varied considerably. While some grew fond of one another and created strong, amicable, or even family-like bonds (Brinker, 2020), other relationships remained weak and rather formal. In that case, the intermediary often stepped in as a friend, especially in the absence of other strong ties. In this sense, intermediaries, who were initially weak ties, indeed took over the role of strong ties in their absence, as previously theorised (see Section 2):

It is nice. She [intermediary] is not like a landlord [referring to host]. She helps me with a lot of things related to my living situation. She is a very good person. Very empathetic. Before quarantine, we often met to have a coffee and talk. She is a good person, more like a friend, not just a volunteer. (Hamza, refugee)

As refugees in Refugees Welcome have not fully completed the asylum process, they regularly have appointments with different entities. Some hosts struggled to support their flatmates in these matters due to their own commitments. Therefore, intermediaries regularly substituted hosts or took full responsibility:

The intermediary is a crucial figure because he provides help on behalf of the organisation if the refugee needs anything specific like preparing a CV, getting in touch with a social worker from the city council, or anything else. Because when Abdallah moved in, he had many appointments and programs [it was important to get some extra help]. (Ignacio, host)

However, intermediaries sometimes struggled with finding an acceptable level of support for the refugee without overstepping boundaries or undermining their autonomy. For instance, Paula recalled how she might have overstepped the line:

They had already prolonged the flatshare, and the host didn't want to continue, and they had agreed on terminating it. We got a little desperate at this point, and I wanted to help him [the refugee].... I knew that he knew that my responsibility as an intermediary wasn't to get him a job, but I could see that he was very desperate. I know he received a lot of support from other organisations, but they didn't advance. So, I started to send out CVs for him [from her e-mail account].... He never told me to do so, but I wasn't sure if he had done it. (Paula, intermediary)

The fine line between adequately supporting and patronising migrants was also expressed by social workers:

One rebound effect is when the intermediary is hyperprotective and generates dependency. In other words, they do everything for the refugee, and it is not the refugee who is making his/her own decisions....It is better if intermediaries tell them I am not the one who is going to do this for you, but I will accompany you. (Gala, social worker)

Overprotection, while well-meant, shows that volunteers, whose role was to intermediate and to contribute to horizontality, could at times reinforce the power imbalance in the family hosting network. To minimise this risk, Refugees Welcome provides training sessions for newly recruited volunteers to explain the asylum application process, the concepts of horizontality and equality in flatshares, and behaviours to avoid, such as overprotecting refugees.

\subsection{Intervening in Host-Refugee Relationships}

In conflict situations, intermediaries intervened by providing advice or a third opinion. Hosts and refugees valued the opportunity to consult with a third and independent party:

It is an important person. And they should be given more importance than they are given....They are not affected by everyday life [in the flatshare]. They are a more independent figure. It is someone who is there, and I know it can be sometimes difficult to step in. But they [hosts and refugees] know they can consult them if things go wrong without burning any relationships. I think it is a figure that should be given more potential. (Belén, host)

Many hosts and refugees emphasised that they preferred to talk to the intermediary first when issues arose. In a disagreement with his flatmate, one host called the intermediary to ask for advice. When asked why he chose to talk to the intermediary instead of the social worker, he emphasised that consulting the social worker would have a "far too formal character." Although the intermediary did not intervene directly, informing her helped him "get the pressure off his chest."

Conflicts usually centred around daily issues in flatshares, such as cleaning, recycling, and rent. For instance, volunteer Katia described that Hamza complained that the rent was higher than previously agreed. Katia discussed the matter with both parties separately, even though it made her feel uneasy:

First, I didn't know how to address it.... I felt uncomfortable, but I could see that Hamza was very uncomfortable talking about the money issue. But in the beginning, we had agreed with the host on a way of paying, and later, he [host] changed it. He never said things clearly, so I felt uncomfortable. (Katia, intermediary)

As indicated before, hosts and social workers cherished direct intervention and the flow of information. Refugees 
seldom called for direct intervention but emphasised the importance of having someone to turn to if they had a problem and the value of a safe environment through having an external person monitor the flatshare. While intermediaries were crucial for refugees' sense of safety, they often struggled with their roles and expectations.

\subsection{Struggling With the Role as Intermediary}

Social workers confirmed that there was a high turnover of intermediaries, as can be expected for volunteers. Analysis of the data of thirty-nine flatshares in Catalonia revealed that flatshares were active for 9.8 months on average and terminated after one contract prolongation, as refugees found independent housing. Around 50\% of refugees and hosts stayed in contact with Refugees Welcome after the flatshare ended. However, most intermediaries lost touch with refugees, hosts, and the organisation while the flatshare was still running, despite initially being quite active.

Although the data collected by the organisation does not reveal why intermediaries left, it showed that intermediaries who stayed in contact were better embedded in the organisation's community through having additional responsibilities or regularly attending meetings. Regular interaction and a sense of belonging can motivate volunteers in emotionally challenging environments (cf. Doidge \& Sandri, 2018).

The interviews showed that increasing demands in intermediaries' personal and professional lives often led to a temporary or permanent interruption of volunteering and the removal of the refugees' newly gained local social capital:

The relationship was good. She lived in my village. So, we met from time to time. But then she found a job and was busy and didn't have time to meet. One day she told me she found a job abroad and moved there. (Azeez, refugee)

Besides, volunteers may struggle with finding the right amount and form of help, as Katia and Paula indicated (see above). Hugo also expressed this fragile balance:

He [intermediary] shouldn't feel like a burden when he steps in and supports the refugee. I think it is essential that the refugee receives help from outside the house... but I also believe that the local buddy should be someone who helps rather than making things more difficult. (Hugo, host)

Furthermore, intermediaries often disengaged when they felt no longer needed. They were commonly the ones initiating meetings with hosts and refugees. Refugees did not want to bother intermediaries and thus waited for them to reach out. One social worker described this discrepancy in communication as a crucial factor in why intermediaries struggle:
Some of them [intermediaries] disappear because the workload increases, some because the flatshare is going well, and they don't feel the need to keep communicating. I think that is the main reason they think everything is going well, so they are not needed. (Gala, social worker)

Intermediaries sometimes felt rejected or unfulfilled if they were not needed. They did not want to be mere bystanders or only check on flatmates through calls or texts. Speaking of an intermediary losing touch, Belén said:

There were a lot of expectations of having quick rewards, of feeling needed....I think he didn't meet the profile of an intermediary... he got very frustrated every time he saw Yolanda [refugee] was very selfefficient because she needed little support. Instead of enjoying her independence, he got frustrated with it....He didn't like the feeling of not feeling needed. (Belén, host)

Intermediaries further reported that they felt closer to migrants and hosts when they had specific tasks.

Emotions and empathy are motivating forces for volunteering with refugees and are often fuelled by sentimental media coverage (cf. Doidge \& Sandri, 2018). Éster described how the organisation's representation of the intermediary's role might influence volunteers' expectations:

I also must be self-critical because we sell it [expectations] to them. When your website says it will be an enriching experience, people think it always will be. There are many expectations by applicants and sometimes also white-saviours, and they won't be part of the project....Sometimes people believe they must help refugees with the language, give them clothes and a job. But some may have everything. They just need asylum in Spain. (Éster, social worker)

Refugees Welcome mainly relies on its social media presence and appearances in the local press to increase host society engagement. To make its mission more tangible, the organisation regularly features stories of hostrefugee relationships on its channel. Sometimes, they asked volunteers to invite refugees and hosts to participate in social media posts by providing photos or videos of living together or spending the COVID-19 lockdown. This role was challenging for some volunteers:

Concerning the social media content, I felt a bit obligated to pass them on to the family. Then I saw that it was bothering them a lot because I sent them a couple per week, and they didn't want to do any. They stopped responding to me. Well, this has all been quite counterproductive... and now I don't know how to continue. (Mila, intermediary) 
Thus, intermediaries' expectations towards their responsibilities might not always match their value to the flatshare and the organisation. One way to avoid high dropout was by recruiting volunteers mainly within the organisation's circle of friends and acquaintances or from other refugee organisations, as another unit in Spain did. However, previous friendship ties between hosts and intermediaries, which sometimes existed, made intermediaries less independent.

\section{Conclusion}

Homestay programs offer a way to provide refugees safe and stable housing and facilitate access to local social capital and mutual cultural learning. Yet, while they often enable refugees to create strong ties with hosts, they can also-even simultaneously-reproduce power imbalances. This article explores the impact of intermediaries on the host-refugee dyad, analysing whether intermediaries can compensate for potential power imbalances.

Refugees Welcome uses intermediaries with the aim to extend the support network of asylum seekers and refugees, provide a security net to host-refugee relationships, and promote the "welcoming culture" as ambassadors of social inclusion. My results showed, first, that intermediaries were regarded by all parties as essential bridges in the hosting network. While hosts' and social workers' responsibilities were structured, volunteers' responsibilities differed in each case. This flexibility in tasks and the unique dedication to one flatshare allowed them to give personalised support. Intermediaries often eased the first weeks of co-living, acted as impartial advisers, and provided emotional support, thus effectively providing a safety net for the refugee. Furthermore, intermediaries form a critical link with the organisation. By checking on flatshares periodically and providing social workers with updates, intermediaries enable the organisation to monitor flatshares discretely. Additionally, the organisation relies on volunteers to mediate minor conflicts.

All interviewees indicated that flatshares needed very few direct interventions. Yet, the presence of an independent party provided hosts and refugees with a sense of security. In this sense, intermediaries compensated for power imbalances in host-refugee relationships. However, by overstepping boundaries, volunteers could also reinforce power differentials. Furthermore, amicable relationships between volunteers and hosts jeopardised the neutrality of intermediaries. Lastly, volunteers often disengaged when they felt un-needed. These results suggest that the value of intermediation by volunteers depends ultimately on the extent to which volunteers have no previous ties to the hosts, have realistic motivations and expectations, and stay engaged.

The results have several implications. First, all parties appreciated the role of intermediaries in host-refugee flatshares, suggesting that this practice may be valu- able for other homestay programs. Second, to maintain intermediaries' independence, social organisations should refrain from instructing volunteers to ask hosts or refugees for favours to support social media campaigns. Furthermore, they should avoid assigning intermediaries who are friends with the hosts. NGOs are encouraged to advertise the role of intermediaries in hosting networks differently from traditional befriending programs, emphasising the importance of a mediator for the hostrefugee dyad. When this article was finalised, the organisation had already changed the description of volunteers and flatshares on their website. Specialised training on conflict mediation in intercultural relationships and interacting with vulnerable communities might enhance the quality of volunteers' support.

Furthermore, attracting a diverse group of volunteers in terms of gender and nationality allows for better matches between intermediaries, hosts, and refugees. Lastly, organisations are encouraged to invest in creating a sense of community among volunteers. By the time this article was completed, Refugees Welcome in Catalonia had introduced quarterly online meetings with volunteers to strengthen the community and keep volunteers informed and engaged.

While homestay programs can be highly beneficial for the incorporation of certain profiles of refugees, especially relatively young, single refugees, they remain small-scale projects compared to the large number of refugees in need of housing and offer only temporary housing. However, while not a viable mass alternative to government-led solutions, they can complement such solutions for specific groups of refugees. Furthermore, the study of intermediation in asymmetrical residentrefugee relationships can be valuable beyond these programs. Both homestay programs and intermediation could be upscaled with more financial support.

Future research could compare Refugees Welcome's approach in Spain with other homestay programs. As Refugees Welcome accommodates refugees who have already spent a minimum of six months in Spain, future research could examine the impact of similar functions at earlier stages of the asylum application process.

\section{Acknowledgments}

I am deeply grateful to the editors and anonymous reviewers of this article for their valuable comments. I would also like to thank Dr Miranda Lubbers for her constructive criticism on earlier drafts of this article. Sincere thanks also to Refugees Welcome Spain who supported me throughout my ethnographic fieldwork and to all participants of this study. All procedures contributing to this work comply with the ethical standards of the relevant national and institutional committees on human experimentation and with the Helsinki Declaration of 1975, as revised in 2008. Ethical approval for data collection was obtained from the university's Institutional Review Board (ID: 5189), the Ethics Committee on Animal and Human 
Experimentation (CEEAH) of the Autonomous University of Barcelona.

\section{Conflict of Interests}

The author declares no conflict of interest.

\section{References}

Adam, F., Foebker, S., Imani, D., Pfaffenbach, C., Weiss, G., \& Wiegandt, C.-C. (2019). “Lost in transition?" Integration of refugees into the local housing market in Germany. Journal of Urban Affairs, 43, 831-850.

Ager, A., \& Strang, A. (2008). Understanding integration: A conceptual framework. Journal of Refugee Studies, 21(2), 166-191.

Behnia, B. (2007). An exploratory study of befriending programs with refugees. Journal of Immigrant \& Refugee Studies, 5(3), 1-19.

Brinker, L.-D. (2020). My home is your home? Power differentials in mixed-status relationships between local hosts and refugees in family hosting programs. Manuscript in preparation.

Charbonneau, J., \& Laaroussi, M. V. (2003). Twinning projects between immigrant families and Quebecois families: Volunteer work, mutual aid, or intervention? Journal of International Migration and Integration, 4(4), 453-470.

Colic-Peisker, V., \& Tilbury, F. (2008). Being Black in Australia: A case study of intergroup relations. Race \& Class, 49(4), 38-56.

Comisión Española de Ayuda al Refugiado. (2021). Proceso de asilo [Asylum process]. https://www.cear.es/ persona-refugiada/proceso-de-asilo

Del Real, D. (2019). Toxic ties: The reproduction of legal violence within mixed-status intimate partners, relatives, and friends. International Migration Review, 53(2), 548-570.

Doidge, M., \& Sandri, E. (2018). 'Friends that last a lifetime': The importance of emotions amongst volunteers working with refugees in Calais. British Journal of Sociology, 70(2), 463-480.

Fingerman, K. (2009). Consequential strangers and peripheral ties: The importance of unimportant relationships. Journal of Family Theory and Review, 1(2), 69-86.

Garthwaite, K. (2016). The perfect fit? Being both volunteer and ethnographer in a UK Foodbank. Journal of Organizational Ethnography, 5(1), 60-71.

Granovetter, M. S. (1973). The strength of weak ties. American Journal of Sociology, 78(6), 1360-1380.

Hebbani, A., Colic-Peisker, V., \& Mackinnon, M. (2018). Know thy neighbour: Residential integration and social bridging among refugee settlers in Greater Brisbane. Journal of Refugee Studies, 31(1), 82-103.

Hill O'Connor, C., \& Baker, R. (2017). Working with and for social enterprises: The role of the volunteer ethnographer. Social Enterprise Journal, 13(2), 180-193.
Kourachanis, N. (2019). From camps to social integration? Social housing interventions for asylum seekers in Greece. International Journal of Sociology and Social Policy, 39(3/4), 221-234.

Liebe, U., Meyerhoff, J., Kroesen, M., Chorus, C., \& Glenk, K. (2018). From welcome culture to welcome limits? Uncovering preference changes over time for sheltering refugees in Germany. PLOS ONE, 13(8). https:// doi.org/10.1371/journal.pone.0199923

Mahieu, R., \& Van Caudenberg, R. (2020). Young refugees and locals living under the same roof: Intercultural communal living as a catalyst for refugees' integration in European urban communities? Comparative Migration Studies, 8(12), 1-17.

Oficina de Asilo y Refugio. (2020). Asilo en cifras 2019 [Asylum in numbers 2019]. Ministerio del Interior, Secretaría General Técnica. http://www.interior.gob. es/documents/642317/1201562/Asilo_en_cifras_ 2019_126150899.pdf/15f04b97-06e9-4ab0-ba20$7 \mathrm{~d} 90 \mathrm{ebec} 1 \mathrm{f} 13$

Phillimore, J., \& Goodson, L. (2008). Making a place in the global city: The relevance of indicators of integration. Journal of Refugee Studies, 21(3), 305-325.

Phillips, D. (2006). Moving towards integration. The housing of asylum seekers and refugees in Britain. Housing Studies, 21(4), 539-553.

Provivienda. (2019). Una casa como refugio: Itinerarios residenciales de las personas solicitantes de protección internacional en Madrid y Vigo [A home like a refuge: Residential itineraries of applicants for international protection in Madrid and Vigo]. https://www.provivienda.org/wp-content/uploads/ INFORME-CIUDADES-ACOGEDORAS-FINAL-28OCTUBRE-LR.pdf

Ran, G. J., \& Join-Lambert, H. (2019). Influence of family hosting on refugee integration and its implication on social work practice: the French case. European Journal of Social Work, 23(3), 461-474.

Refugees Welcome. (2021a). Refugees Welcome. https:// refugees-welcome.es

Refugees Welcome. (2021b). Colabora [Collaborate]. https://refugees-welcome.es/colabora\# colaboramarca

Refugees Welcome. (2021c). Una nueva cultura de bienvenida [A new welcoming culture]. https://refugeeswelcome.es/como-funciona\#nuestrometodo

Refugees Welcome. (2021d). Preguntas frecuentes [Frequent questions]. https://refugees-welcome.es/ como-funciona\#preguntasfrecuentes

Refugees Welcome International. (2021). Refugees Welcome International. https://www.refugeeswelcome.net

Sirriyeh, A. (2013). Hosting strangers: Hospitality and family practices in fostering unaccompanied refugee young people. Child and Family Social Work, 18(1), 5-14.

Stock, I. (2019). Buddy schemes between refugees and volunteers in Germany: Transformative potential 
in an unequal relationship? Social Inclusion, 7(2), $128-138$.

Verdasco, A. (2019). Communities of belonging in the temporariness of the Danish asylum system: Shalini's anchoring points. Journal of Ethnic and Migration
Studies, 45(9), 1439-1457.

Wells, K. (2011). The strength of weak ties: The social networks of young separated asylum seekers and refugees in London. Children's Geographies, 9(3/4), 319-329.

\section{About the Author}

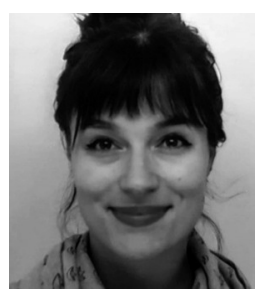

Lara-Désirée Brinker is a PhD candidate at the Department of Social and Cultural Anthropology at the Autonomous University of Barcelona. Her research foci include migration, refugee activism, as well as housing strategies and initial integration measures for vulnerable migrants. She is also a member of the Laboratory of Personal Networks and Communities (egolab-GRAFO), which is part of the Research Group of Fundamentally Oriented Anthropology (GRAFO). 